\title{
Lack of Association between Metabolic Syndrome and Depression in Korean Adults: Analysis Based on the 2016 and 2018 Korean National Health and Nutrition Examination Surveys
}

\author{
Seon Gu Kim, MD', Sung Woo Park, $\mathrm{PhD}^{2,3,4}$, Mi Kyoung Seo, $\mathrm{PhD}^{3}$, Taekjoong Kim, MD, PhD ${ }^{5}$, \\ Jung Goo Lee, MD, PhD ${ }^{1,3,4}$ \\ ${ }^{1}$ Department of Psychiatry, Haeundae Paik Hospital, College of Medicine, Inje University, ${ }^{2}$ Department of Convergence Biomedical Science, \\ College of Medicine, Inje University, ${ }^{3}$ Paik Institute for Clinical Research, Inje University, ${ }^{4}$ Department of Health Science and Technology, \\ Graduate School, Inje University, ${ }^{5}$ Department of Humanities and Social Sciences in Medicine, College of Medicine, Inje University, Busan, \\ Korea
}

Background: This study aims to investigate the relationship between metabolic syndrome and depression in Korean adults using data from the 2016 and 2018 Korean National Health and Nutrition Examination Surveys (KNHANES).

Methods: The total number of participants in the 7th period 1st year (2016) and 3rd year (2018) surveys of KNHANES was 16142. This study was conducted with 10,722 subjects who met the diagnostic criteria for metabolic syndrome and responded to the Patient Health Questionnaire-9 (PHQ-9). Analysis of covariance was used to adjust the differences due to demographic factors, laboratory findings, and underlying diseases to understand the relationship between metabolic syndrome and PHQ-9 scores, if any.

Results: The prevalence of metabolic syndrome was determined to be $25.6 \%$ in this study. The PHQ-9 scores with and without metabolic syndrome were 2.56 and 2.48 , respectively, and there was no significant difference when the confounding variable was corrected $(\mathrm{p}=0.406)$. According to the analysis of each $\mathrm{PHQ}-9$ item and metabolic syndrome, the results were not significant.

Conclusion: In this cross-sectional study conducted in Korean adults, no significant correlation was found between metabolic syndrome and depression.

Keywords Depression; Patient Health Questionnaire-9; Metabolic syndrome; Korea

\section{INTRODUCTION}

According to the 2016 mental illness survey conducted in Korea, the lifetime prevalence and the annual prevalence of depression were $5.0 \%$ and $1.5 \%$, respectively [1]. In a 2018 Statistics Korea survey, 26.6 per 100,000 people died of suicide, more than double the 2016 average for Organization for Economic Cooperation and Development of 11.5 [2]. Depression not only affects daily life and social functions, but is also closely related to suicide [3], so the high suicide rate in Korean society highlights the need for depression assessment and management.

Metabolic syndrome is a multifactorial syndrome composed of risk factors for cardiovascular disease and diabetes, which is defined as abdominal obesity, increased triglycerides, decreased high-density cholesterol, increased fasting blood sugar, and increased blood pressure [4]. Discussions of the relationship between

Received June 25, 2020, Revised August 11, 2020, Accepted September 13, 2020

Correspondence: Jung Goo Lee, MD, PhD

Department of Psychiatry, Haeundae Paik Hospital, College of Medicine, Inje University, 875 Haeun-daero, Haeundae-gu, Busan 48108, Korea

TEL +82-51-890-6749 FAX +82-51-894-6709 E-mail iybihwc@naver.com ORCID https://orcid.org/0000-0003-3393-2667

Copyright $@$ by Korean Society for Affective Disorders. All Rights reserved.

This is an Open Access article distributed under the terms of the Creative Commons Attribution Non-Commercial License (http://creativecommons.org/licenses/ by-nc/4.0/) which permits unrestricted non-commercial use, distribution, and reproduction in any medium, provided the original work is properly cited. 
metabolic syndrome and depression have been raised. For example, Insulin resistance, Hypercotisolemia, Immunoinflammatory activity, oxidative stress, and autonomic dysregulation are presumed to be pathophysiology shared by metabolic syndrome and depression $[5,6]$. A meta-analysis of cross-sectional studies confirmed a significant relationship between metabolic syndrome and depression, but the studies included were limited to most of the Americas and European countries [7,8]. However, In a study conducted in China and Taiwan, the relationship between metabolic syndrome and depression was not significant $[9,10]$.

The Patient Health Questionnaire-9 (PHQ-9) is a depression screening tool consisting of 9 major Depression Diagnostic Criteria items in the Diagnosis and Statistics Manual: Mental Disorders, 4th Edition of the Patient Health Questionnaire developed by Kroenke et al. [11]. In the diagnosis of depression, $88 \%$ sensitivity and $88 \%$ specificity were reported, and Korean studies also reported high levels of reliability and validity with similar levels of sensitivity and specificity [12-14]. In addition, PHQ-9 is likely to be used as a useful tool for screening and evaluating depression because it has fewer questions and easier scoring than other depression assessment tools [14].

Since 2014, the Korean National Health and Nutrition Examination Survey (KNHANES) has adopted PHQ9 as a screening tool for depression in the mental health area and included it in the 2014, 2016, and 2018 survey items. As a result, it was possible to perform a meaningful analysis in the mental health field compared to the previous survey that only confirmed the presence or absence of depression [15]. In this study, we investigate the relationship between metabolic syndrome and depression in Korean adults using data from the 2016 and 2018 KNHANES. The relationship between each item of PHQ-9 and metabolic syndrome was also examined.

\section{MATERIALS AND METHODS}

We utilized raw data from the 7th period 1st year (2016) and the 3rd year (2018) of the KNHANES. KNHANES has been approved by the Institutional Review Board of Korea Centers for Disease Control and Prevention and has been conducted every three years since 1998, and has been conducted annually since 2007 . The data consist of health surveys, health examinations and nutrition surveys. Health surveys investigate disease morbidity, medical use, smoking, drinking, and mental health, and health examinations include body measurements, blood pressure and pulse measurements, and blood and urine tests. Of the total 16,142 participants in 2016 and 2018, 10,722 adults were selected. This study was conducted with the approval of Institutional Review Board for Human Research, Haeundae Paik Hospital, Inje University (HPIRB 2020-05-023).

\section{Subjects}

Among the 2016 and 2018 KNHANES subjects, the inclusion criteria for this study were adults between the ages of 19 and 80 who performed all measures for the diagnosis of metabolic syndrome and responded to all items of PHQ-9. We excluded cases in which any of the tests corresponding to the diagnostic criteria of metabolic syndrome were missing or answered 'no idea' to the items in PHQ-9. The total number of study subjects according to the criteria was 10,722 .

\section{Measurements}

\section{1) Metabolic syndrome}

The definition of metabolic syndrome empolyed in this study was modified in waist circumference from the definition of the American Heart Association/National Heart, Lung and Blood Institute [16] to Korean standards. The following criteria were applied: 1) Elevated waist circumference $(>102 \mathrm{~cm}[>90 \mathrm{~cm}$ for Asians] for men, $>88 \mathrm{~cm}$ [ $>85 \mathrm{~cm}$ for Asians] for women); 2) Elevated triglycerides $(\geq 150 \mathrm{mg} / \mathrm{dL}$, drug treatment for elevated triglycerides is an alternative indicator); 3 ) Reduced high-density lipoprotein (HDL) cholesterol $(<40 \mathrm{mg} / \mathrm{dL}$ in men, $<50 \mathrm{mg} / \mathrm{dL}$ in women, drug treatment for reduced HDL is an alternative indicator); 4) Elevated blood pressure $(\geq 130 \mathrm{mmHg}$ [systolic blood pressure] $/ \geq 85 \mathrm{mmHg}$ [diastolic blood pressure], antihypertensive drug treatment in a patient with hypertension is an alternative indicator); 5) Elevated fasting glucose $(\geq 100 \mathrm{mg} / \mathrm{dL}$, drug treatment of elevated glucose is an alternative indicator). When three or more of them were met, metabolic syndrome was diagnosed.

\section{2) Depression}

Korean version of the PHQ-9 was used to evaluate depressive symptoms. The primary outcome was the rela- 
tionship between the total score of PHQ-9 and metabolic syndrome. In order to confirm the relationship between the severity of depression and the metabolic syndrome, the total score of PHQ-9 was classified as minimal from 0 to 5 , mild from 5 to 9 , and moderate to severe from 10 .

\section{3) Demographic and confounding variables}

Age, sex, marital status, employment status, income level, education level, drinking, smoking, and exercise were included in the analysis as demographic characteristics. Income levels were divided into above and below average. Education level was classified based on college or higher education. It was checked whether or not drinking more than one drink per month in the last year and smoking for 5 packs or more for a lifetime. The exercise was checked at least 75 minutes aerobic exercise more than once a week.

In addition to the items involved in the diagnosis of metabolic syndrome, laboratory findings such as hemoglobin, white blood cell (WBC), platelet, aspartate transaminase (AST), alanine transaminase (ALT), blood urea nitrogen (BUN), creatinine, and high-sensitivity Creactive protein (hsCRP) levels were also analyzed. Underlying diseases such as stroke, myocardial infarction, angina pectoris, thyroid disease, chronic kidney disease, cirrhosis and cancer were included in the analysis.

\section{4) Statistical analyses}

Age and laboratory findings were compared using an independent t-test. Sex and underlying disease status were compared through a chi-square test. To analyze the correlation between the severity of depression and metabolic syndrome, a linear by linear association analysis was performed. Variables with statistically significant differences between the group with and without metabolic syndrome were considered as confounding variables, analysis of covariance was performed for the PHQ-9 score and metabolic syndrome. Statistical significance of this study was defined as $p<0.05$ in both directions, and IBM SPSS Statistics for Windows, Version 23.0 (IBM Co., Armonk, NY, USA) was used for all statistical analysis.

\section{RESULTS}

\section{Demographic data}

In the group with metabolic syndrome, age was older, the proportion of males and married people was higher, and the employment rate was lower. The proportion of high average income of individual and household were lower in group with metabolic syndrome, and the education level was higher. Monthly drinking was lower in the group with metabolic syndrome, but lifelong smoking was higher in group with metabolic syndrome. The exercise rate was lower in the group with metabolic syndrome (Table 1).

\section{Laboratory findings}

Hemoglobin, WBC, AST, ALT, BUN, and hsCRP were all significantly higher in the group with metabolic syndrome, except platelet (Table 2).

Table 1. Demographic characteristics of the subjects with and without metabolic syndrome

\begin{tabular}{|c|c|c|c|c|c|}
\hline \multirow{2}{*}{ Demographic characteristics } & \multirow{2}{*}{$\begin{array}{l}\text { Total sample } \\
(n=10722)\end{array}$} & \multicolumn{2}{|c|}{ Metabolic syndrome } & \multirow{2}{*}{$\begin{array}{l}\text { Statistical } \\
\text { coefficient }\end{array}$} & \multirow{2}{*}{$p$-value } \\
\hline & & Yes $(n=2742)$ & No $(n=7980)$ & & \\
\hline Age (y) & $51.13(16.64)$ & $57.57(14.61)$ & $48.00(16.60)$ & $t=21.040$ & $<0.001$ \\
\hline Male & $4,743(44.2)$ & $1,449(52.8)$ & $3,294(41.3)$ & $\chi^{2}=110.679$ & $<0.001$ \\
\hline Married & $8,965(83.6)$ & $2,557(93.3)$ & $6,408(80.3)$ & $\chi^{2}=249.874$ & $<0.001$ \\
\hline Employed & $6,586(61.4)$ & $1,560(56.9)$ & $5,026(63.0)$ & $\chi^{2}=31.940$ & $<0.001$ \\
\hline Above average income (individual) & $5,405(50.4)$ & $1,322(48.2)$ & $4,083(51.2)$ & $\chi^{2}=7.116$ & 0.008 \\
\hline Above average income (household) & $6,125(57.1)$ & $1,277(46.6)$ & $4,848(60.8)$ & $\chi^{2}=167.541$ & $<0.001$ \\
\hline College or above & $3,967(37.0)$ & $658(24.0)$ & $3,309(41.5)$ & $\chi^{2}=267.177$ & $<0.001$ \\
\hline Drinking alcohol (monthly) & $5,826(54.3)$ & $1,432(52.2)$ & $4,394(55.1)$ & $\chi^{2}=6.625$ & 0.010 \\
\hline Smoking (lifetime) & $4,100(38.2)$ & $1,287(46.9)$ & $2,813(35.3)$ & $\chi^{2}=118.005$ & $<0.001$ \\
\hline Exercise & $4,642(43.3)$ & 983 (35.8) & $3,659(45.9)$ & $\chi^{2}=83.166$ & $<0.001$ \\
\hline
\end{tabular}

Values are presented as mean (standard deviation) or number (\%). 
Table 2. Laboratory findings of the subjects with and without metabolic syndrome

\begin{tabular}{|c|c|c|c|c|c|}
\hline \multirow{2}{*}{ Laboratory findings } & \multirow{2}{*}{$\begin{array}{c}\text { Total sample } \\
(n=10,722)\end{array}$} & \multicolumn{2}{|c|}{ Metabolic syndrome } & \multirow{2}{*}{$\begin{array}{l}\text { Statistical } \\
\text { coefficient }\end{array}$} & \multirow{2}{*}{$p$-value } \\
\hline & & Yes $(n=2,742)$ & No $(n=7,980)$ & & \\
\hline $\mathrm{Hb}$ & $14.05(1.61)$ & $14.36(1.61)$ & $13.94(1.60)$ & $t=11.63$ & $<0.001$ \\
\hline WBC & $6.29(1.77)$ & $6.74(1.76)$ & $6.13(1.75)$ & $t=15.64$ & $<0.001$ \\
\hline Plt & $260.45(63.33)$ & $260.35(64.26)$ & $260.48(63.02)$ & $t=-0.09$ & 0.926 \\
\hline AST (IU/L) & $23.26(14.44)$ & $27.33(20.19)$ & $21.86(11.51)$ & $t=13.46$ & $<0.001$ \\
\hline ALT (IU/L) & $22.47(17.38)$ & $29.41(20.69)$ & 20.09 (15.38) & $t=21.61$ & $<0.001$ \\
\hline BUN (mg/DI) & $14.90(4.81)$ & $16.06(5.27)$ & $14.50(4.57)$ & $t=13.83$ & $<0.001$ \\
\hline Creatinine $(\mathrm{mg} / \mathrm{dL})$ & $0.82(0.25)$ & $0.87(0.30)$ & $0.80(0.22)$ & $t=11.67$ & $<0.001$ \\
\hline $\mathrm{HsCRP}(\mathrm{mg} / \mathrm{L})$ & $1.21(2.12)$ & $1.55(2.34)$ & $1.09(2.03)$ & $t=9.10$ & $<0.001$ \\
\hline
\end{tabular}

Values are presented as mean (standard deviation).

$\mathrm{Hb}$, hemoglobin; WBC, white blood cell; Plt, platelet; AST, aspartate transaminase; ALT, alanine transaminase; BUN, blood urea nitrogen; hsCRP, high-sensitivity C-reactive protein.

Table 3. Underlying diseases of the subjects with and without metabolic syndrome

\begin{tabular}{lccccc}
\hline \multirow{2}{*}{ Underlying diseases } & Total sample & \multicolumn{2}{c}{ Metabolic syndrome } & Statistical \\
& $(n=10,722)$ & Yes $(n=2,742)$ & No $(n=7,980)$ & coefficient & $p$-value \\
\cline { 3 - 4 } & $238(2.2)$ & $125(4.6)$ & $113(1.4)$ & $\chi^{2}=92.863$ & $<0.001$ \\
Stroke & $310(2.9)$ & $153(5.6)$ & $157(2.0)$ & $\chi^{2}=94.854$ & $<0.001$ \\
Myocardial infarction and angina & $413(3.9)$ & $110(4.0)$ & $303(3.8)$ & $\chi^{2}=0.254$ & 0.614 \\
Thyroid disease & $32(0.3)$ & $15(0.5)$ & $17(0.2)$ & $\chi^{2}=7.651$ & 0.006 \\
Chronic kidney disease & $37(0.3)$ & $9(0.3)$ & $28(0.4)$ & $\chi^{2}=0.030$ & 0.861 \\
Liver cirrhosis & $523(4.9)$ & $156(5.7)$ & $367(4.6)$ & $\chi^{2}=5.228$ & 0.022 \\
\hline Cancer & & & & &
\end{tabular}

Values are presented as number (\%).

Table 4. PHQ-9 depression severity of the subjects with and without metabolic syndrome

\begin{tabular}{lcrr}
\hline PHQ-9 depression severity* & $\begin{array}{c}\text { Total sample } \\
(n=10,722)\end{array}$ & \multicolumn{2}{c}{ Metabolic syndrome } \\
\cline { 2 - 4 } & $81.1 \%$ & $80.7 \%$ & No $(n=7,980)$ \\
\hline Minimal & $13.6 \%$ & $12.8 \%$ & $81.2 \%$ \\
Mild & $5.3 \%$ & $6.4 \%$ & $13.8 \%$ \\
\hline Moderate to Severe & & $5.0 \%$ \\
\hline
\end{tabular}

PHQ-9, Patient Health Questionnaire-9.

Minimal: total PHQ-9 score $<5$. Mild: total PHQ -9 score $\geq 5$ and $<10$. Moderate to severe: total $P H Q-9$ score $\geq 10$. $\star p=0.058$.

\section{Underlying diseases}

The cancer category incorporated the results of liver cancer, colorectal cancer, breast cancer, cervical cancer, lung cancer, thyroid cancer and other cancers. Stroke, myocardial infarction and angina, chronic kidney disease, and cancer showed significantly higher prevalence in the group with metabolic syndrome. The prevalence of Thyroid disease and Liver cirrhosis was not signifi- cantly different between the two groups (Table 3).

\section{Metabolic syndrome and PHQ-9}

Table 4 shows the relationship between the severity of depression and the metabolic syndrome as a linear by linear association. The proportion of moderate to severe depression was 1.4 percentage points higher in the group with metabolic syndrome (6.4\% vs. $5.0 \%)$, but did not 
show a significant difference with a p-value of 0.058 . Analysis of covariance was performed to compare PHQ9 scores according to the presence or absence of metabolic syndrome, and the results are described in Table 5 and Table 6 . The following variables, which had significant differences between the two groups, were used as confounding variables. All variables of demographic data, all variables of laboratory findings except platelet, and stroke, myocardial infarction and angina, chronic kidney disease, cancer among underlying diseases. In the group with and without metabolic syndrome, the total score of PHQ-9 was not significantly different when the covariate was corrected ( 2.56 to $2.48, \mathrm{p}=0.406$, Table $5)$. In the group with and without metabolic syndrome, each item of PHQ-9 also showed no significant difference (Table 6).

\section{DISCUSSION}

In this study, the prevalence of metabolic syndrome in Korean adults was $25.6 \%$, and using 10 points of PHQ-9 as cut-off, the prevalence of depression was $5.3 \%$ (Table 4). When the relationship between metabolic syndrome and depression was calculated, the ratio of moderateto-severe depression was $1.4 \%$ higher in metabolic syndrome, but did not show statistical significance when compared with the PHQ total score. The total score of PHQ-9 was also 2.56 points and 2.48 points in the group with and without metabolic syndrome, 0.08 points higher in the group with metabolic syndrome, but this was also not a significant difference.

In the study of the American and European countries, the relationship between metabolic syndrome and depression was continuously reported and confirmed in

Table 5. PHQ-9 total score of the subjects with and without metabolic syndrome

\begin{tabular}{|c|c|c|c|c|c|c|}
\hline & \multirow{2}{*}{$\begin{array}{c}\text { Total sample } \\
(n=10,722)\end{array}$} & \multicolumn{2}{|c|}{ Metabolic syndrome } & \multirow{2}{*}{$\begin{array}{l}\text { Statistical } \\
\text { coefficient }\end{array}$} & \multirow{2}{*}{$\mathrm{p}$-value } & \multirow{2}{*}{$\begin{array}{l}\text { Adjusted- } \\
\text { p-value* }\end{array}$} \\
\hline & & Yes $(n=2,742)$ & No $(n=7,980)$ & & & \\
\hline PHQ-9 total score & $2.50(3.64)$ & $2.56(3.94)$ & $2.48(3.53)$ & $t=0.883$ & 0.377 & 0.406 \\
\hline
\end{tabular}

Values are presented as mean (standard deviation).

PHQ-9, Patient Health Questionnaire-9.

*Adjusted for the effects of demographic characteristics (age, sex, marriage, employment, income, education, alcohol consumption, smoking, and exercise), laboratory findings (level of hemoglobin, white blood cell, aspartate transaminase, alanine transaminase, blood urea nitrogen, creatinine, and high-sensitivity C-reactive protein), and underlying diseases (stroke, myocardial infarction and angina, chronic kidney disease, cancer).

Table 6. PHQ-9 sub-item scores of the subjects with and without metabolic syndrome

\begin{tabular}{|c|c|c|c|c|c|}
\hline \multirow{2}{*}{ PHQ-9 sub-item scores } & \multirow{2}{*}{$\begin{array}{c}\text { Total sample } \\
(n=10,722)\end{array}$} & \multicolumn{2}{|c|}{ Metabolic syndrome } & \multirow{2}{*}{$\begin{array}{c}\text { Difference } \\
\text { between means }\end{array}$} & \multirow{2}{*}{$\begin{array}{l}\text { Adjusted } \\
\text { p-valuex }\end{array}$} \\
\hline & & Yes $(n=2,742)$ & No $(n=7,980)$ & & \\
\hline Sub-item 1. Loss of interest & $0.34(0.73)$ & $0.31(0.74)$ & $0.35(0.73)$ & -0.04 & 0.895 \\
\hline Sub-item 2. Depressive mood & $0.25(0.62)$ & $0.25(0.67)$ & $0.25(0.60)$ & 0.00 & 0.676 \\
\hline Sub-item 3. Change of sleep & $0.55(0.96)$ & $0.60(1.00)$ & $0.54(0.89)$ & 0.06 & 0.058 \\
\hline Sub-item 4. Decreased energy & $0.63(0.91)$ & $0.60(0.96)$ & $0.65(0.89)$ & -0.05 & 0.952 \\
\hline Sub-item 5. Change of appetite & $0.28(0.68)$ & $0.28(0.71)$ & $0.28(0.67)$ & 0.00 & 0.106 \\
\hline Sub-item 6. Self-blame & $0.17(0.54)$ & $0.18(0.58)$ & $0.17(0.52)$ & 0.01 & 0.997 \\
\hline Sub-item 7. Decreased concentration & $0.12(0.48)$ & $0.13(0.57)$ & $0.12(0.46)$ & 0.01 & 0.978 \\
\hline Sub-item 8. Psychomotor change & $0.07(0.36)$ & $0.09(0.43)$ & $0.06(0.34)$ & 0.03 & 0.396 \\
\hline Sub-item 9. Suicide or self-harm & $0.09(0.39)$ & $0.12(0.48)$ & $0.08(0.36)$ & 0.04 & 0.416 \\
\hline
\end{tabular}

Values are presented as mean (standard deviation).

PHQ-9, Patient Health Questionnaire-9.

*Adjusted for the effects of demographic characteristics (age, sex, marriage, employment, income, education, alcohol consumption, smoking, and exercise), laboratory (level of hemoglobin, white blood cell, aspartate transaminase, alanine transaminase, blood urea nitrogen, creatinine, and high-sensitivity C-reactive protein), and underlying diseases (stroke, myocardial infarction and angina, chronic kidney disease, cancer). 
the meta-analysis $[7,8]$. Significant results were also reported in two prospective cohort studies conducted in Japan $[18,19]$ and a cross-sectional study based on KNHANES in 2014 and 2016 in Korea [20]. However, in cross-sectional studies in Asia such as China and Taiwan, insignificant results were reported $[9,10]$. As there are not many studies conducted on Asians about the relationship between metabolic syndrome and depression, it is thought that there will still be limitations to establish a clear correlation as in Western studies. In addition, the discrepancy between the reports raises the need to consider socio-cultural backgrounds such as races, genetic effects or life styles of different cultures in the study of metabolic syndrome and depression.

The study also has limitations. Since this study was conducted based on a large-scale epidemiological survey of general adults in Korea, it has the advantage of having a large number of samples and analyzing various demographic fators. However, this study is a retrospective cross-sectional study based on epidemiological investigations already conducted, so it is difficult to identify the causal relationship between metabolic syndrome and depression. In addition, because the epidemiological investigation (KNHANES) was not designed for the study of metabolic syndrome and depression, it is difficult to completely exclude bias even though various confounding factors are controlled. Because, among the studies conducted in Asia, two cohort studies conducted in Japan showed a significant correlation between metabolic syndrome and depression, but no significant results were reported in cross-sectional studies conducted in China and Taiwan. Therefore, in order to clearly identify the relationship between metabolic syndrome and depression in the adult population of Korea in the future, it is believed that additional prospective studies will be helpful as well as continuously tracking epidemiological findings.

\section{CONCLUSION}

Most studies have shown that metabolic syndrome is associated with depression, but there are also reports that there are no significant differences among races or cultures. In this study, we tried to investigate the relationship between metabolic syndrome and depression in Korean adults using epidemiological surveys in 2016 and 2018, but could not find any significant correlation between them. However, considering the limitations of the study mentioned above, future research on the relationship between metabolic syndrome and depression in Korean adults is expected to require a prospective study that considers racial and genetic trends, life style, as well as demographic variables.

\section{CONFLICTS OF INTEREST}

The authors have nothing to disclose.

\section{ORCID}

\author{
Seon Gu Kim \\ https://orcid.org/0000-0003-1580-6093 \\ Sung Woo Park \\ https://orcid.org/0000-0001-8601-9084 \\ Mi Kyoung Seo \\ https://orcid.org/0000-0002-3368-4950 \\ Taekjoong Kim \\ https://orcid.org/0000-0002-3926-3735 \\ Jung Goo Lee \\ https://orcid.org/0000-0003-3393-2667
}

\section{REFERENCES}

1. Hong JP. The survey of mental disorders in Korea 2016. Sejong: Ministry of Health \& Welfare; 2017.

2. Statistics Korea (KOSTAT). 2018 Annual report on the causes of death [Internet]. Daejeon: Statistics Korea; 2019 Sep 24 [cited 2020 Jun 4]. Available from: http://kostat. go.kr/portal/korea/kor_nw/1/6/2/index.board?bmode=read $\& b S e q=\& a S e q=377606 \&$ page $\mathrm{No}=1 \&$ row $\mathrm{Num}=10 \&$ navCo unt $=10 \&$ currPg $=\&$ searchInfo $=\&$ sTarget $=$ title \&sTxt $=$

3. Jeon HJ. Depression and suicide. J Korean Med Assoc 2011; 54:370-5.

4. Kassi E, Pervanidou P, Kaltsas G, Chrousos G. Metabolic syndrome: definitions and controversies. BMC Med 2011; 9:48.

5. McIntyre RS, Rasgon NL, Kemp DE, Nguyen HT, Law $\mathrm{CW}$, Taylor $\mathrm{VH}$, et al. Metabolic syndrome and major depressive disorder: co-occurrence and pathophysiologic overlap. Curr Diab Rep 2009;9:51-9.

6. John G, Asghari M, Vipin VP, Eapen V. Depression and metabolic syndrome: two sides of the same coin. J Biomed Clin Res 2019;12:3-9.

7. Pan A, Keum N, Okereke OI, Sun Q, Kivimaki M, Rubin $\mathrm{RR}$, et al. Bidirectional association between depression and 
metabolic syndrome: a systematic review and meta-analysis of epidemiological studies. Diabetes Care 2012;35:117180 .

8. Ghanei Gheshlagh R, Parizad N, Sayehmiri K. The relationship between depression and metabolic syndrome: systematic review and meta-analysis study. Iran Red Crescent Med J 2016;18:e26523.

9. Yu S, Yang H, Guo X, Zheng L, Sun Y. Metabolic syndrome and depressive symptoms among rural Northeast general population in China. BMC Public Health 2017;17:43.

10. Chang H, Hsiao T, Lien M, Yeh C, Yang H. Metabolic syndrome and depression are not correlated: results from a community sample exploring the unique and common correlates for the two diseases. Neuropsychiatry 2017;7:142-8.

11. Kroenke K, Spitzer RL, Williams JB. The PHQ-9: validity of a brief depression severity measure. J Gen Intern Med 2001;16:606-13.

12. Choi HS, Choi JH, Park KH, Joo KJ, Ga H, Ko HJ, et al. Standardization of the Korean version of Patient Health Questionnaire-9 as a screening instrument for major depressive disorder. J Korean Acad Fam Med 2007;28:114-9.

13. Lee SH, Huh YJ, Kim JH, Han C. Finding optimal cut off points of the Korean version of the Patient Health Questionnaire-9(PHQ-9) for screening depressive disorders. Mood Emot 2014;12:32-6.

14. Park SJ, Choi HR, Choi JH, Kim KW, Hong JP. Reliability and validity of the Korean version of the Patient Health Questionnaire-9 (PHQ-9). Anxiety Mood 2010;6:119-24.

15. Park SJ, Roh S, Hwang J, Kim HA, Kim S, Lee TK, et al. Association between depression and metabolic syndrome in
Korean women: results from the Korean national health and nutrition examination survey (2007-2013). J Affect Disord 2016;205:393-9.

16. Alberti KG, Eckel RH, Grundy SM, Zimmet PZ, Cleeman JI, Donato KA, et al. Harmonizing the metabolic syndrome: a joint interim statement of the International Diabetes Federation Task Force on Epidemiology and Prevention; National Heart, Lung, and Blood Institute; American Heart Association; World Heart Federation; International Atherosclerosis Society; and International Association for the Study of Obesity. Circulation 2009;120:1640-5.

17. Lee SY, Park HS, Kim DJ, Han JH, Kim SM, Cho GJ, et al. Appropriate waist circumference cutoff points for central obesity in Korean adults. Diabetes Res Clin Pract 2007; 75:72-80.

18. Takeuchi T, Nakao M, Nomura K, Inoue M, Tsurugano S, Shinozaki $\mathrm{Y}$, et al. Association of the metabolic syndrome with depression and anxiety in Japanese men: a 1-year cohort study. Diabetes Metab Res Rev 2009;25:762-7.

19. Morikawa M, Okamoto N, Kiuchi K, Tomioka K, Iwamoto J, Harano A, et al. Association between depressive symptoms and metabolic syndrome in Japanese communitydwelling older people: a cross-sectional analysis from the baseline results of the Fujiwara-kyo prospective cohort study. Int J Geriatr Psychiatry 2013;28:1251-9.

20. Kim Y, Kim HY. Association between depression and metabolic syndrome in Korean adults: data from the 2014 and 2016 Korea National Health and Nutrition Examination Survey. Asia Pac J Public Health 2019;31:18-29. 